\title{
COMBINATION SELECTION OF ISTANBUL ATATURK AIRPORT
}

\author{
Orhan Ertugrul Guclu, Cem Cetek \\ Anadolu University \\ Eskisehir, Turkey \\ E-mail: oeguclu@anadolu.edu.tr, ccetek@anadolu.edu.tr
}

\begin{abstract}
Rapidly increasing demand for air transportation leads serious capacity problems at major airports like delays and congestions. Especially determining the suitable runways for the airport operations sometimes causes essential problems such as airport ground traffic congestions, air pollution due to exhaust emission and noise pollution. These are the main results of wrong runway selection. Conventional runway selection is done by only wind direction. In conventional method; noise pollution reduction, exhaust emission pollution reduction and ground traffic congestion reduction haven't been considered. In our research, we have studied on Istanbul Ataturk Airport. Istanbul Atatürk Airport has three runways for flight operations. These runways are operated for over 100 million passengers annually. Approximately 1200 aircraft operation are executed daily in Istanbul Ataturk Airport. But ground traffics mainly face with the congestions and delays. The reason of these congestions and delays is the wrong combination of runways. Up until now, this selection is done by only wind direction. Besides the wind direction there should be additional criteria for the best selection of runway combination. In this decision making process; noise prevention criteria, exhaust emission reducing criteria and possible critical points that face with the congestions will be used. By the help of these criteria, the selection of the runway combination will be done with Analytic Hierarchy Process (AHP). When we detail on the analysis, we could have reduced the effect of the exhaust emission, noise pollution and the possible delays and congestions with considering these effects.
\end{abstract}

Keywords: Runway, Istanbul Ataturk Airport, Noise Prevention, Exhaust Emission, Delay, Congestion. 


\section{Introduction}

In many airport, there are lots of operational failures such as aircraft taxi management, gate allocation, ground services management, and the runway combination selection. The runway combination selection is the essential unsolved problem for many airports. Because it has different disciplines for solving this problem. Istanbul Ataturk Airport is one of the airports, which have the runway combination selection problem. It has three runways that have for civil aviation usage. Generally in Atatürk Airport, air traffic controllers prefer the combination in the essence of only wake turbulence effects. They do not consider the noise pollution, exhaust emission and the airport gridlock points. In this paper, we have analyzed that runway combination selection with the criteria of wind direction, noise pollution, exhaust emission and some points in the airport that effect the taxi traffic by the help Analytic Hierarchy Process.

\section{Literature Review}

Dimitris Bertsimas, Michael Frankovich, Amedeo Odoni has presented a mixed integer programming for optimal selection of airport runway configurations [1]. But they have only considered to solve the problem of arrival/departure runway balancing. Sze-Wei Chang has studied on the initial construction of runways according to available land, existing obstructions, topographic difficulties, flight path interference, noise pollution and other environmental affects [2]. Chang's study was on the new building of an airport or a runway. Gary W. Lohr, Sherilyn Brown, H. Paul Stough, Steve Eisenhawer, Dou Long and Steve Atkins has studied on a System Oriented Runway Management (SORM) concept that has been developed to address the critical part of the traffic flow process [3]. But they haven't studied on the affects of the noise and exhaust pollution.

\section{Hypotheses/Objectives}

In our study we have considered the essential criteria of runway combination selection. These are the wind direction, gridlock points on the airport, noise pollution and the exhaust pollution. These criteria's have been analyzed with Analytic Hierarchy Process. By the help of our analysis, best runway combination will be selected for Istanbul Ataturk Airport having more then a thousand flight operations.

\section{Research Design/Methodology}

Our AHP model is created with the essential criteria of the runway combination selection. These criteria are, as I mentioned, wind direction, noise and exhaust pollution and some critical points at the airports, which causes air traffic controllers to pay more attention during their working period. And these criteria are created by a survey, which is done to twelve air traffic controllers who had some period working in Istanbul Atatürk Airport. The result of the survey gave us the importance of the criteria among them. These importance parameters are created with their arithmetical averages.

\section{Data/Model Analysis}

According to our model we have eight criteria. Four of them refer to critical points. Two of them are for noise pollution. And the remaining ones are for the exhaust emission. In International Symposium of 
Istanbul Ataturk Airport, there are three runways. Besides this there are four possible runway selection. Runway 17 , runway 35, runway 23 and runway 05 are the possible runway selections. Criterion 1 refers to the holding point of runway 35 , criterion 2 refers to runway 17, criterion 3 refers to runway 23 and the criterion 4 refers to runway 05 . Criterion 5 refers to the noise reduction effect of runway 17. Criterion 6 refers to the noise reduction effect of runway 23. Remaining two criteria are criterion 7 for exhaust emission effect of runway 17 and criterion 8 for positive exhaust emission effect of runway 23 . The table below shows us the weights of these eight criteria.

\begin{tabular}{|l|c|}
\hline & Criteria Weight5 \\
\hline 1. Criterion & 0,087417597 \\
\hline 2. Criterion & 0,108058608 \\
\hline 3. Criterion & 0,08474359 \\
\hline 4. Criterion & 0,126373626 \\
\hline 5. Criterion & 0,141025641 \\
\hline 6. Criterion & 0,152014657 \\
\hline 7. Criterion & 0,148451648 \\
\hline 8. Criterion & 0,152014652 \\
\hline Tota! & 1 \\
\hline
\end{tabular}

\section{Limitations}

Besides these criteria, we should make more complex model, which has more criteria. These criteria are the possible weather change during a period. But we only get the wind direction. And also we should add the criteria of ground traffic effect at the apron caused by the congestions of the departure and arrival aircraft. These criteria are only be created by watching the airport for 24 hours a day.

\section{Conclusions}

According to our study, we could have managed how to select the best runway combination for Istanbul Ataturk Airport. But this model can be designed to the other airports. When we look at the airports that have the capacity problem always face with the wrong selection of the runway combination. Detailed analysis of runway selection can reduce the effects of noise pollution, exhaust emission and possible ground delays on the airport.

\section{Key References}

List here only those 3 to 5 references that are key for the study at hand. As an example:

[1] Dimitris Bertsimas, Michael Frankovich, Amedeo Odonis (2011), Volume 59 Issue 6, 11-12 2011 Pages 1407-1419, Journal Operation Research 
IJAHP Article: Mu, Saaty/A Style Guide for Paper Proposals To Be Submitted to the International Symposium of the Analytic Hierarchy Process 2014, Washington D.C., U.S.A.

[2] Sze-Wei CHANG, Orientations Optimization for two Runway Configurations, Proceedings of the Eastern Asia Society for Transportation Studies, Vol.9, 2013

[3] Gary W. Lohr, Sherilyn Brown, H. Paul Stough, Steve Eisenhawer, Dou Long and Steve Atkins, System Oriented Runway Management: A Research Update, Ninth USA/Europe Air Traffic Management Research and Development Seminar (ATM2011) 